University of Nebraska - Lincoln

DigitalCommons@University of Nebraska - Lincoln

2012

Predatory Identity Can Explain Nest Predation Patterns

Jennifer L. Reidy

University of Missouri - Columbia, jennifer_reidy@gmail.com

Frank Thompson

USDA Forest Service Nothern Research Station, frthompson@fs.fed.us

Follow this and additional works at: https://digitalcommons.unl.edu/usgsnpwrc

Part of the Other International and Area Studies Commons

Reidy, Jennifer L. and Thompson, Frank, "Predatory Identity Can Explain Nest Predation Patterns" (2012). USGS Northern Prairie Wildlife Research Center. 256.

https://digitalcommons.unl.edu/usgsnpwrc/256

This Article is brought to you for free and open access by the US Geological Survey at DigitalCommons@University of Nebraska - Lincoln. It has been accepted for inclusion in USGS Northern Prairie Wildlife Research Center by an authorized administrator of DigitalCommons@University of Nebraska - Lincoln. 


\title{
Predatory Identity Can Explain Nest Predation Patterns
}

\author{
Jennifer L. Reidy and Frank R. Thompson III
}

Abstract. Knowledge of dominant predators is necessary to identify predation patterns and mitigate losses to nest predation, especially for endangered songbirds. We monitored songbird nests with timelapse infrared video cameras at Fort Hood Military Reservation, Texas, from 1997 to 2002 and 2005, and in Austin, Texas, during 2005, 2006, 2008, and 2009. Predation was the most common source of nest failure. We identified 13 species of predators during 126 predation events. Snakes were the most frequent nest predator group $(n=48)$, followed by birds $(n=25)$, fire ants $(n=22)$, cowbirds $(n=15)$, and mammals $(n=14)$. We evaluated models predicting probability of predation by five predator groups that represented two groups of hypotheses: temporal and nest activity factors, and habitat and landscape factors. Snake and fire ant predation primarily occurred at night, whereas bird predation occurred during the day. Mammal predation occurred during both day and night. Predicted nest predation by birds, cowbirds, and mammals decreased throughout the breeding season, but predation by fire ants and snakes increased. Predation was highest on older nestlings ( $>6$ days old) by all predator groups except fire ants, which depredated young nestlings more. The percent urban land class in the landscape and nest height affected predator groups at shrub and canopy nests differently. Bird and snake predation increased for canopy nesters with increasing urbanization and nest height. Cowbird predation increased for shrub nesters with increasing urbanization and nest height, and increased with greater percent of open land use in the landscape for both guilds. We found no good predictor of mammal predation, likely because small and meso-mammals were lumped. We suggest future investigations of nest predation either identify predators, or at least consider who the likely predators are, and consider predator-specific hypotheses.

Key Words: Black-capped Vireo, cowbirds, endangered species, fire ants, Golden-cheeked Warbler, predation risk, predator identity, snakes, video cameras.
$\mathrm{P}$ redation is often the leading cause of nest failure for passerines (Newton 1998, Thompson 2007). High predation rates can limit productivity of a population and have been implicated as a possible source of declining songbird populations (Brawn and Robinson 1996, Newton 2004, Adams et al. 2007, Thompson 2007). Despite substantial efforts to correlate predation rates to habitat and landscape features, few general trends have emerged, and most are

Reidy, J. L., and F. R. Thompson III. 2012. Predatory identity can explain nest predation patterns. Pp. 135-148 in C. A. Ribic, F. R. Thompson III, and P. J. Pietz (editors). Video surveillance of nesting birds. Studies in Avian Biology (no. 43), University of California Press, Berkeley, CA. 
related to temporal factors or nest stage. Study conclusions are conflicting and often study-site or regionally specific (Thompson 2007, Lahti 2009), causing some to speculate that nest predation is random or unpredictable (Filliater et al. 1994, Wilson and Cooper 1998). Factors affecting predation differ across habitats and regions and are confounded by spatial and temporal scales studied (Thompson 2007). Additionally, patterns may be obscured by lumping predator species (Benson et al. 2010). Knowledge of dominant predators in study systems is necessary to identify predation patterns and mitigate losses to nest predation if possible (Thompson 2007, Campomizzi et al. 2009, Richardson et al. 2009, Benson et al. 2010).

Recent advances in the development of miniature video technology have enabled researchers to document nest predators at active nests in locations and habitats across the planet (Richardson et al. 2009). The primary objective of video monitoring studies has been to identify nest predators and secondarily to quantify rates of nest failure (Thompson and Burhans 2003, Reidy et al. 2008). Despite increased knowledge of local predator species, few studies have evaluated factors affecting predation rates by predator groups (Thompson and Burhans 2003, Benson et al. 2009), likely because of a small number of predations by multiple predators. Often such studies have short durations and small spatial scales, thereby limiting sample size and possible inference. Long-term data ( $\geq 3 \mathrm{yrs}$ ) and spatial replication are necessary to understand temporal and spatial trends in predator composition and importance. If nest predation is a limiting factor, such information is vital for managing and protecting bird species (Adams et al. 2007, Thompson 2007), particularly birds of conservation concern (Carter et al. 2007, Benson et al. 2010).

Black-capped Vireos (Vireo atricapilla; hereafter vireo) and Golden-cheeked Warblers (Setophaga chrysoparia; hereafter warbler) are federally endangered species with restricted breeding ranges. Vireos breed in short scrubland dominated by oaks (Quercus spp.) found in central and southcentral Texas, with small, isolated populations elsewhere (Grzybowski 1995). They build nests $0.5-2 \mathrm{~m}$ off the ground in shrubs within dense patches of deciduous scrub (Grzybowski 1995). The warbler's breeding range is entirely confined to Ashe juniper (Juniperus ashei)-oak woodlands and adjacent edges in central Texas (Ladd and Gass 1999). Warblers build nests 3-15 m above ground (Reidy et al. 2009), typically in the upper two-thirds of junipers (Ladd and Gass 1999). Habitat preferences differ between the species, but they are often found in adjacent patches or together in highly heterogeneous patches of juniper-oak. Both species are known to be victims of Brown-headed Cowbird (Molothrus ater) parasitism (Pulich 1976, Grzybowski 1995), and vireos are especially vulnerable to parasitism (U.S. Fish and Wildlife Service 1991).

Nest site, habitat, and landscape factors affect nest success (Thompson et al. 2002), but specific effects may vary by predator. Nest height may partition the types of predators able to access nests, such that non-arboreal predators would be more likely to depredate nests placed in shrubs and arboreal predators would be more likely to depredate nests in the canopy. The nesting substrate may affect predator species if nests are more concealed in certain substrates than others (Martin 1993). Warbler nests are made of junipers (Ladd and Gass 1999), and those built in junipers may be more difficult for visually oriented predators to locate. On the contrary, vireos select for (Bailey and Thompson 2007) and experience slightly higher survival in deciduous substrates than junipers (Bailey 2005), suggesting structural differences among mature and immature junipers, oaks, and other deciduous species may expose canopy and shrub nests to different suites of predators. Larger-scale variables such as landscape composition may also affect predator groups. Abundance and movements of predators vary among habitats (Chalfoun et al. 2002) and may constrain the availability of predators at smaller spatial scales such as the nest site (Thompson et al. 2002). Cowbirds favor humanaltered and fragmented landscapes (Robinson et al. 1995), and their importance as potential nest predators has recently been emphasized (Arcese et al. 1996, Granfors et al. 2001). Red imported fire ants (Solenopsis invicta) thrive in disturbed habitats (Plowes et al. 2007) and are negatively impacting wildlife populations wherever they occur (Allen et al. 2004, Conner et al. 2010).

Additionally, temporal factors are known to influence nest survival (Bailey and Thompson 2005, Grant et al. 2005, Reidy et al. 2009) and may be important predictors of predator groups. Variables such as day of year and time may affect predation risk because of different seasonal and daily foraging and activity patterns by major 
predator groups such as snakes (Sperry et al. 2008) and fire ants (Vogt et al. 2003). Additionally, risk of failure due to cowbirds is likely associated with their peak laying season in May (Robinson et al. 1995). Predator groups may also use different cues to locate nests. Many studies have concluded that nest survival differed by stage (Burhans et al. 2002, Williams and Wood 2002, Conner et al. 2010), often with higher predation during the nestling stage. Nests with young have stronger auditory, olfactory, and visual cues related to sounds, smells, and movements associated with aging nestlings (Martin et al. 2000). Hence, predation could also vary within as well as between stages (Williams and Wood 2002, Grant et al. 2005).

We pooled observations of predation events based on video surveillance from studies in central Texas (Stake and Cimprich 2003, Stake et al. 2004, Reidy et al. 2008) to have sufficient sample size to look at some predator-specific patterns in predation not investigated by the original studies. We hypothesized that the effects of habitat, landscape, and temporal factors on the probability of nest predation would vary among predator groups. We could only look at a limited number of habitat and landscape variables that were common across all studies. Thus, we consider this study exploratory; however, it and other recent studies (Benson et al. 2010) should help form the basis for predator-specific hypotheses for future studies.

\section{METHODS}

Data used for this analysis was gathered by multiple studies, and some results are reported in Stake and Cimprich (2003), Stake et al. (2004), and Reidy et al. $(2008,2009)$. Nests were monitored at multiple sites at Fort Hood, Texas $\left(30^{\circ} 10^{\prime} \mathrm{N}, 97^{\circ} 45^{\prime} \mathrm{W}\right)$, from March to July 1997-2002 and 2005 and in Austin, Texas $\left(30^{\circ} 23^{\prime} \mathrm{N}, 97^{\circ} 47^{\prime} \mathrm{W}\right)$, from March to June during 2005, 2006, 2008, and 2009 (Fig. 11.1). Fort Hood is an 88,500 -ha active military base where nesting habitat of vireos and warblers occurs as discrete patches surrounded by grassland and agriculture in the north and includes some urbanized areas in the south. Vireos and warblers co-occur in patches suitable to both species, but typically are found at higher densities in different habitats and, therefore, sites were monitored for one or the other species. Austin is a large and rapidly urbanizing city, located $\sim 113 \mathrm{~km}$ south of Fort Hood. We focused on warblers

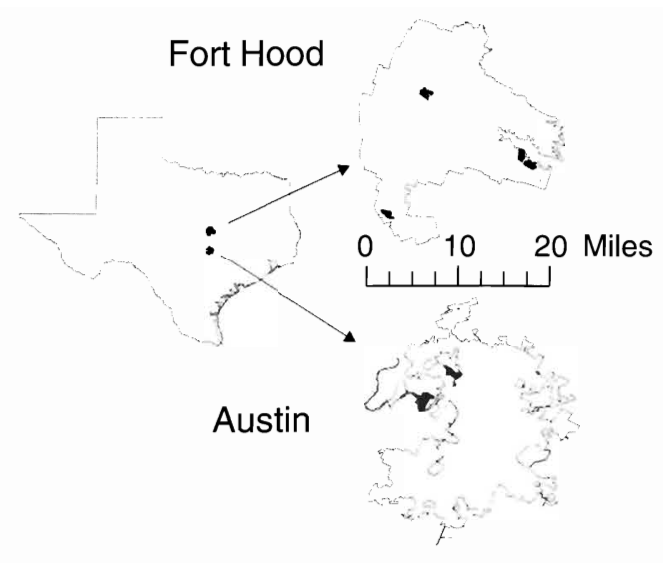

Figure 11.1. Study areas (black) at Fort Hood (light gray) and Austin (dark gray), Texas, from 1997-2009.

in Austin, where large juniper-oak patches in western Austin are being fragmented by urban and residential development. Cowbird control was used at several of the sites at Fort Hood and Austin and therefore results may not be representative of areas with no cowbird control.

The same general monitoring methodology was followed for all studies after 1998. Cameras camouflaged with tape or tight-fitting sleeves were deployed at nests in the afternoons and positioned $\sim 30-50 \mathrm{~cm}$ from the nest, overhead if possible. Because camera setup during the building and laying stages was a source of abandonment at vireo nests, after 1998 setup was delayed until after laying was complete (Stake and Cimprich 2003, Stake et al. 2004). To prevent additional abandonment, we removed camera equipment after 1-2 hrs if the pair had not resumed normal nesting activity. Recording equipment was placed $>15 \mathrm{~m}$ from the nest, and after initial placement of cameras, nests were monitored at the recording equipment. Tapes were scanned daily to determine nesting activity. If a nest had been disturbed, we scanned the tape more fully to determine the cause; if the nest was depredated, we identified predators to species. Additional study site and monitoring details can be found elsewhere (Stake and Cimprich 2003, Stake et al. 2004, Reidy et al. 2009).

We defined a predator visit that resulted in any change to the nest contents as a predation event. Additionally, we considered predator visits resulting in no change to nest contents as a predation event if the nesting pair abandoned the nest shortly after a visit or young force-fledged (nestlings left prematurely as a result of the presence of a predator 
at the nest) (unlike previous analyses using some of this data; see Stake and Cimprich 2003, Stake et al. 2004, Reidy et al. 2009). Otherwise, predator visits were not considered a predation event and were not included in analyses. We included multiple predator predation events and repeat events made by the same predator species over $>24 \mathrm{hrs}$ as separate predation events. We classified final nest outcome as: abandoned if parents abandoned nests after laying was initiated; depredated if the nest failed due to predation event(s); failed due to weather events; fledged if $\geq 1$ host young left the nest on its own (including if nest was partially depredated); and force-fledged if $\geq 1$ host young left the nest prematurely due to presence of predator. We coded the fate of each individual interval as depredated (1) or not depredated (0).

We categorized species by nesting guild (canopy or shrub). Most nests monitored were vireo or warbler nests, but to increase the sample size of predation events, we also included nests of other songbirds that were monitored with cameras. We partitioned nests into egg (laying and incubating) and nestling (nestling and fledging) stages to evaluate predation risk by stage. We were not able to determine exact nest age for all nests, so to evaluate effects of nest age, we subdivided the nestling stage into young nestlings ( $\leq 6$ days old) and old nestlings ( $>6$ days old) and evaluated the effect of three age categories (egg, young or old nestlings). We recorded the plant species (substrate) the nest was placed in and measured nest height $(\mathrm{m})$. We were missing nest heights for 12 nests. Deleting observations because of a missing value for an independent variable can result in greater bias than imputing a value (Allison 2002). Because few values were missing, we used a simple approach, a single random imputation (Allison 2002). For each missing nest height, we assigned random nest heights from a normal distribution based on the mean and standard deviation for the appropriate nesting species. We calculated percent composition of landcover types within $5 \mathrm{~km}$ of each nest in ArcMap 9.2 (ESRI, Redlands, CA) using the Texas Ecological Systems Classification Project map (German et al. 2009). We collapsed cover types to wooded/shrubland (representing nesting habitat), open (grassland, agriculture, barren), and urban (high and low density).

We categorized predation events as cowbirds, birds (excluding cowbirds), fire ants, mammals, and snakes for use as the response variable in our analysis. While different species likely have unique predation patterns, we were unable to evaluate our hypotheses by species due to small sample size of many species. Predator groups were composed of one to four species (Table 11.1). We used multinomial logistic regression to simultaneously model effects of hypothesized factors on the probability of predation by each predator group. We built 12 models to represent our temporal and nest activity hypotheses. Temporal factors were day of year, year*guild (because we did not monitor both guilds in all years), and time (diurnal or nocturnal). We compared support for a linear, quadratic, or cubic effect of day of year and included the most supported form in the final model set. Factors related to activity at the nest were nest stage or nest age. Because these variables are correlated, stage and age were used in separate models. We initially examined 11 models with a single variable or interaction that represented our habitat and landscape hypotheses. Nest-site factors were nest height and nest substrate (juniper, oak, or other). Landscape factors were percent open, percent urban, and percent wooded cover within a $5-\mathrm{km}$ radius of the nest. We used a likelihood ratio test to determine if the global model was a significant improvement over a constant survival model (intercept-only model) and proceeded with model selection if it was. We ranked model support using Akaike's information criterion (AIC) and report $-2 \times \log$-likelihood $[-2(\ln L)]$, $\Delta$ AIC, and Akaike weights $\left(w_{\mathrm{i}}\right)$ for all models (Burnham and Anderson 2002). We focused interpretation on the most plausible models $(\Delta \mathrm{AIC}<5)$ and evaluated the contribution of each variable by considering evidence ratios for the model with and without a variable (Burnham and Anderson 2002). This application of evidence ratios directly assesses the importance of a variable without assumptions about the distribution of a variable or selection of an alpha or confidence level (D. R. Anderson, pers. comm.). We interpret effects for supported variables by plotting the probability of predation by each predator group across the range of observed values (Table 11.2; Shaffer and Thompson 2007).

\section{RESULTS}

We monitored 305 nests for 3,346 camera nestdays (1,379 in egg and 1,967 in nestling stages); camera nest-days are the number of days active nests were monitored with video surveillance 
TABLE 11.1

Predator groups and species by nesting guild (canopy or shrub) and nesting stage (egg or nestling) of songbird nests monitored with video cameras at several sites in central Texas, 1997-2009.

\begin{tabular}{|c|c|c|c|c|c|}
\hline \multirow[b]{2}{*}{ Predator } & \multicolumn{2}{|c|}{ Canopy } & \multicolumn{2}{|c|}{ Shrub } & \multirow[b]{2}{*}{ Tota } \\
\hline & Egg & Nestling & Egg & Nestling & \\
\hline Birds (excluding cowbirds) & 5 & 10 & 2 & 8 & 25 \\
\hline American Crow (Corvus brachyrhynchos) & 4 & 0 & 0 & 0 & 4 \\
\hline Broad-winged Hawk (Buteo platypterus) & 0 & 0 & 0 & 3 & 3 \\
\hline Cooper's Hawk (Accipiter cooperii) & 0 & 3 & 0 & 0 & 3 \\
\hline Western Scrub-Jay (Aphelocoma californica) & 1 & 7 & 2 & 5 & 15 \\
\hline Brown-headed Cowbirds (Molothrus ater) & 1 & 1 & 5 & 8 & 15 \\
\hline Fire ants (Solenopsis invicta) & 0 & 2 & 5 & 15 & 22 \\
\hline Mammals & 1 & 7 & 2 & 4 & 14 \\
\hline Fox squirrel (Sciurus niger) & 1 & 7 & 0 & 0 & 8 \\
\hline Gray fox (Urocyon cinereoargenteus) & 0 & 0 & 0 & 4 & 4 \\
\hline Mouse (Peromyscus sp.) & 0 & 0 & 1 & 0 & 1 \\
\hline Ringtail (Bassariscus astutus) & 0 & 0 & 1 & 0 & 1 \\
\hline Snakes & 4 & 22 & 3 & 19 & 48 \\
\hline Great Plains ratsnake (Pantherophis emoryi) & 1 & 0 & 0 & 0 & 1 \\
\hline Texas ratsnake (Pantherophis obsoletus) & 3 & 22 & 3 & 16 & 44 \\
\hline Western coachwhip (Coluber flagellum testaceus) & 0 & 0 & 0 & 3 & 3 \\
\hline Unidentified & 0 & 0 & 0 & 1 & 1 \\
\hline Unknown predator & 1 & 0 & 0 & 1 & 2 \\
\hline Total & 11 & 42 & 17 & 54 & 124 \\
\hline
\end{tabular}

NOTE: Snake taxonomy is from Crother (2008).

TABLE 11.2

Mean, standard error (SE), and minimum and maximum values of continuous covariates used in analyses of predation risk of camera-monitored songbird nests in central Texas, 1997-2009.

\begin{tabular}{|c|c|c|c|c|c|c|c|c|}
\hline \multirow[b]{2}{*}{ Variable } & \multicolumn{4}{|c|}{ Canopy } & \multicolumn{4}{|c|}{ Shrub } \\
\hline & Mean & SE & Min & $\operatorname{Max}$ & Mean & SE & Min & Max \\
\hline Percent urban & 22.1 & 0.6 & 0.4 & 65.5 & 6.5 & 0.2 & 0.4 & 22.1 \\
\hline Percent open & 16.5 & 0.3 & 1.2 & 35.9 & 26.6 & 0.1 & 18.7 & 43.3 \\
\hline Percent wooded & 44.9 & 0.3 & 21.2 & 63.7 & 48.0 & 0.2 & 24.6 & 61.8 \\
\hline Nest height (m) & 5.3 & 0.0 & 2.2 & 12.2 & 0.9 & 0.0 & 0.2 & 1.9 \\
\hline Day of year & 122 & 0.4 & 91 & 171 & 145 & 0.6 & 98 & 209 \\
\hline
\end{tabular}

NOTE: Day of year is chronological day beginning with January 1 as day 1. 
TABLE 11.3

Number of nests and final outcome by species for songbird nests monitored with cameras in central Texas, 1997-2009.

\begin{tabular}{|c|c|c|c|c|c|c|c|c|}
\hline \multirow[b]{2}{*}{ Species } & \multirow[b]{2}{*}{ Guild } & \multirow[b]{2}{*}{$n$} & \multicolumn{6}{|c|}{ Final outcome } \\
\hline & & & $\mathrm{P}$ & A & W & UF & UO & F \\
\hline $\begin{array}{l}\text { Black-capped Vireo } \\
\text { (Vireo atricapilla) }\end{array}$ & Shrub & 142 & 48 & 19 & 3 & 1 & 8 & 63 \\
\hline $\begin{array}{l}\text { Blue-gray Gnatcatcher } \\
\text { (Polioptila caerulea) }\end{array}$ & Canopy & 3 & 2 & 0 & 0 & 0 & 0 & 1 \\
\hline $\begin{array}{l}\text { Golden-cheeked Warbler } \\
\text { (Setophaga chrysoparia) }\end{array}$ & Canopy & 155 & 37 & 5 & 1 & 0 & 4 & 108 \\
\hline $\begin{array}{l}\text { Northern Cardinal } \\
\text { (Cardinalis cardinalis) }\end{array}$ & Canopy & 2 & 1 & 0 & 0 & 0 & 1 & 0 \\
\hline $\begin{array}{l}\text { Painted Bunting } \\
\text { (Passerina ciris) }\end{array}$ & Shrub & 1 & 0 & 0 & 0 & 0 & 0 & 1 \\
\hline $\begin{array}{l}\text { White-eyed Vireo } \\
\text { (Vireo griseus) }\end{array}$ & Shrub & 2 & 0 & 1 & 0 & 0 & 0 & \\
\hline
\end{tabular}

NOTE: For final outcome, $\mathrm{P}=$ predation, $\mathrm{A}=$ abandon, $\mathrm{W}=$ weather, $\mathrm{UF}=$ failure due to unknown cause, $\mathrm{UO}=$ unknown outcome, $\mathrm{F}=$ fledged (includes nests that fledged $\geq 1$ host young, classified as force fledged).

systems. We verified the outcome of 292 nests, of which 164 nests successfully fledged all young (Table 11.3). We documented 126 predation events (29 in egg stage and 97 in nestling stage) resulting in 88 failed nests and 10 nests that were force-fledged. The remaining nests failed due to abandonment $(n=25)$, weather events $(n=4)$, and unknown $(n=1)$. We attributed four abandonments to predator visits (three by fire ants and one by a cowbird) and included these as predation events. We identified 13 predator species from 124 predation events; snakes were the primary predator group, followed by birds (excluding cowbirds) and fire ants (Table 11.1). We were unable to determine final fate for 13 nests due to theft or equipment failure. Snake predations caused five of ten force-fledgings and three of four predations after $\geq 1$ young had already fledged. The remaining force-fledgings were attributed to mammals $(n=2)$, fire ants $(n=2)$, and birds $(n=1)$. We documented an additional 27 visits by predators to inactive nests, differing by nesting guild (reported in Stake and Cimprich 2003, Stake et al. 2004, Reidy et al. 2009).

\section{Nest Predation}

We were unable to include time of predation in the temporal and nest activity model set because we had too few predations in some categories to fit the model. Nocturnal and diurnal predations occurred with equal frequency $(n=63$ and 61, respectively). All predations by birds (including cowbirds) and $79 \%$ by mammals were diurnal, while $86 \%$ by fire ants and $85 \%$ by snakes were nocturnal.

We found the most support for a linear effect of day of year. For the temporal and nest activity model set, the likelihood ratio test indicated support for the global model over the intercept-only model $\left(\chi_{20}^{2}=92.84, P<0.0001\right)$. The model with day of year, nest age, and year*guild had overwhelming support (Table 11.4). Evidence ratios were $623,1,429$, and 6,374 for models with year*guild, day of year, and age, respectively, versus the model without the variable, indicating models with these factors were $>600$ times more supported than models without them. Risk of predation was highest for old nestlings by all predator groups throughout the season for canopy and shrub nests, except for fire ants, which preyed on young nestlings slightly more than old nestlings (Fig. 11.2). Probability of predation by birds, cowbirds, and mammals decreased marginally throughout the season, while predation by fire ants and snakes increased (Fig. 11.2). On average, nest survival was similar for canopy nests $(0.97$; 95\% CI: $0.96-0.98)$ and shrub nests (0.96; $95 \%$ CI: 0.95-0.97). 
TABLE 11.4

Model support for temporal and nest activity factors affecting predation risk by predator group at songbird nests monitored with cameras in central Texas, 1997-2009.

\begin{tabular}{lcccc}
\hline Model & $K$ & $-2(\ln L)$ & $\Delta$ AIC & $w_{i}$ \\
\hline Day of year + age + year*guild & 25 & $1,339.44$ & 0.00 & 0.98 \\
Day of year + stage + year*guild & 20 & $1,357.32$ & 7.88 & 0.02 \\
Day of year + age & 20 & $1,362.31$ & 12.87 & 0.00 \\
Age + year*guild & 20 & $1,363.97$ & 14.53 & 0.00 \\
Day of year + year*guild & 15 & $1,376.96$ & 17.52 & 0.00 \\
Day of year + stage & 15 & $1,379.94$ & 20.50 & 0.00 \\
Stage + year*guild & 15 & $1,381.54$ & 22.10 & 0.00 \\
Age & 15 & $1,390.33$ & 30.89 & 0.00 \\
Day of year & 10 & $1,402.08$ & 32.64 & 0.00 \\
Year*guild & 10 & $1,406.44$ & 37.00 & 0.00 \\
Stage & 10 & $1,407.80$ & 38.36 & 0.00 \\
Intercept only & 5 & $1,432.28$ & 52.84 & 0.00 \\
\end{tabular}

NOTE: We monitored 54, 44, 38, and 9 Black-capped Vireo nests in 1998, 1999, 2000, and 2001; 1, 3, 2, 6, 31, 24, 31, 44, 8, and 10 Golden-cheeked Warbler nests in 1997, 1998, 1999, 2000, 2001, 2005, 2006, 2008, and 2009; 2 White-eyed Vireos and 1 Painted Bunting in 1999; and 3 Blue-gray Gnatcatchers and 2 Northern Cardinals in 2005.

For the nest-site and landscape model set, we did not include nesting substrate because nest substrate was confounded with nesting guild. Most canopy nests were in junipers and most shrub nests were in oaks (Table 11.5). The likelihood ratio test indicated support for the global model over the intercept-only model $\left(\mathrm{X}_{20}^{2}=\right.$ 58.44, $P<0.001$ ). Upon examination of the initial model results, we built two post-hoc models consisting of an additive combination of two variables: the variable in the most supported model plus the variable from the second and third most supported models. The resulting top two models accounted for a combined Akaike weight of 0.93 and included the variables percent urban*guild and nest height*guild (Table 11.6). The evidence ratio for the additive model with percent urban*guild + nest height*guild versus the model with just nest height*guild was 457 and for the model with percent urban*guild + nest height*guild versus just percent urban*guild was 5 , indicating strong support for both variables. The evidence ratio for the model with percent urban*guild + percent open versus the model with just percent urban*guild was 0.4 , indicating the model with percent open had less than half the support of the model without it, but there was some uncertainty about its lack of importance. Predicted predation by birds and snakes increased with higher amounts of urbanization in the landscape for nests in the canopy, while predation by fire ants decreased (Fig. 11.3). Risk of cowbird predation was higher on shrub nests in areas with greater urban land use (Fig. 11.3). For canopy nests, predicted predation increased as nest height increased for snakes, birds, and mammals (Fig. 11.4), but confidence intervals overlapped. For shrub nests, fire ant predation increased with increasing nest height, while other predator groups showed little difference in predation rates (Fig. 11.4). Risk of predation by mammals was unaffected by extent of urbanization for either guild. The potential effect of percent open was driven by a risk of predation by cowbirds that increased from 0.00 ( $95 \% \mathrm{CI}: 0.00-0.00)$ to 0.03 (95\% CI: 0.01-0.06) with a change in percent open from $0 \%$ to $40 \%$, based on the best model (Table 11.6).

\section{DISCUSSION}

We were able to identify patterns related to temporal, nest activity, and landscape features by different predator groups. A previous analysis using 


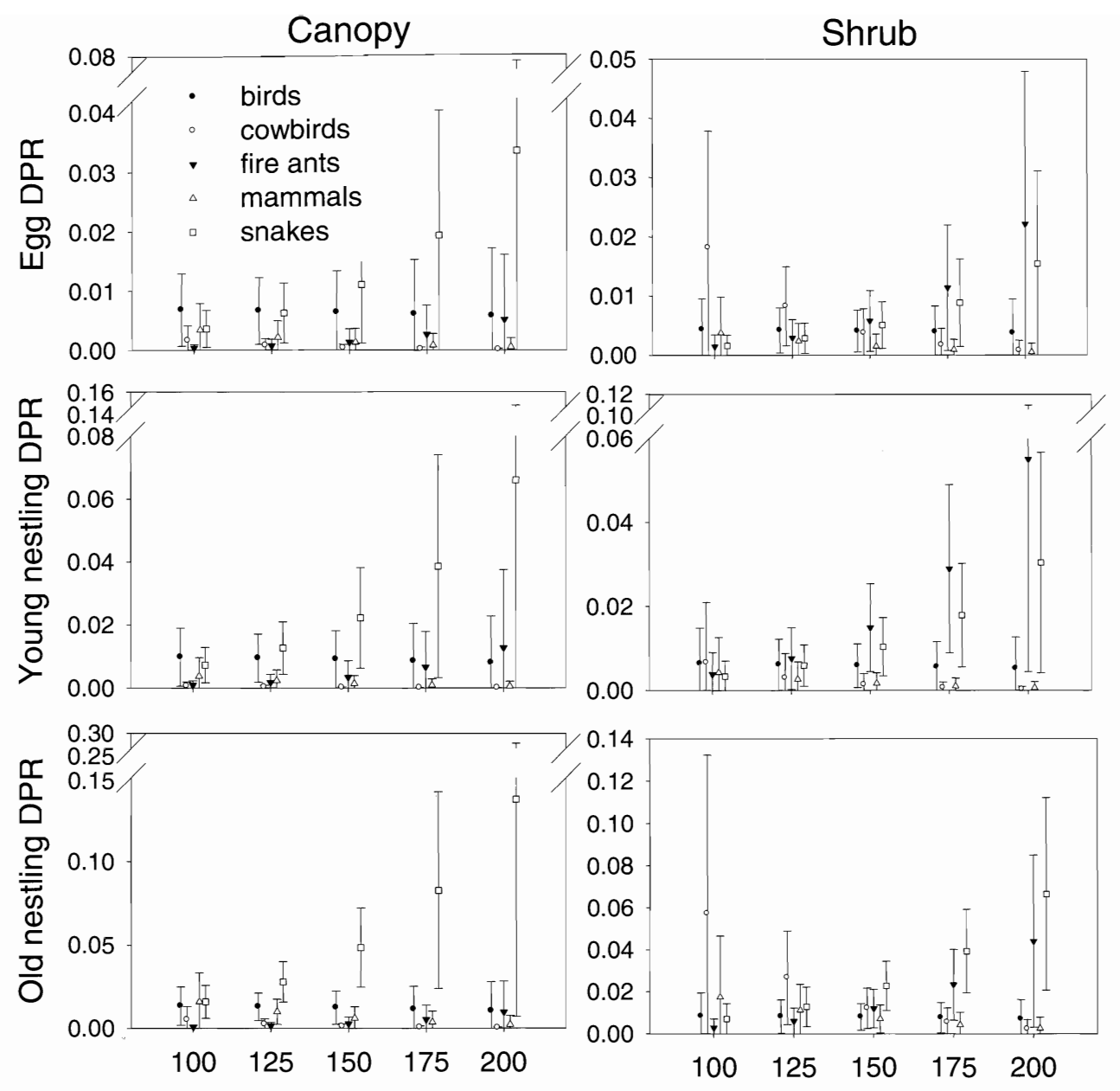

Figure 11.2. Predicted daily predation rate (DPR) and $95 \%$ confidence intervals as a function of day of year and nest age (first row = egg, second row = young nestlings, third row = old nestling) of canopy and shrub nests monitored with video cameras in central Texas, 1997-2009.

TABLE 11.5

Number of nests monitored and depredated by predator groups in juniper, oak, and other substrates by nesting stratum for songbird nests monitored with cameras in central Texas, 1997-2009.

\begin{tabular}{lcccccccc}
\hline & \multicolumn{3}{c}{ Canopy } & & \multicolumn{3}{c}{ Shrub } & \\
\cline { 2 - 4 } & Juniper & Oak & Other & & Juniper & Oak & Other & Total \\
\hline No. nests & 141 & 12 & 7 & & 4 & 94 & 47 & 305 \\
No. depredated & 45 & 4 & 5 & & 1 & 49 & 22 & 126 \\
Birds & 13 & 1 & 1 & & 1 & 8 & 1 & 25 \\
Cowbirds & 1 & 0 & 1 & & 0 & 10 & 3 & 15 \\
Fire ants & 1 & 0 & 1 & & 0 & 13 & 7 & 22 \\
Mammals & 7 & 1 & 0 & & 0 & 3 & 3 & 14 \\
Snakes & 23 & 1 & 2 & & 0 & 14 & 8 & 48 \\
\hline
\end{tabular}


TABLE 11.6

Model support for nest-site and landscape factors affecting predation risk by predator group at songbird nests monitored with cameras in central Texas, 1997-2009.

\begin{tabular}{lcccc}
\hline Model & $K$ & $-2(\ln L)$ & $\Delta$ AIC & $w_{i}$ \\
\hline Percent urban*guild + nest height*guild & 15 & $1,382.73$ & 0.00 & 0.78 \\
Percent urban*guild & 10 & $1,396.08$ & 3.35 & 0.15 \\
Percent urban*guild + percent open & 15 & $1,387.79$ & 5.06 & 0.06 \\
Percent open & 10 & $1,402.18$ & 9.45 & 0.01 \\
Nest height*guild & 10 & $1,404.98$ & 12.25 & 0.00 \\
Percent open*guild & 10 & $1,406.12$ & 13.39 & 0.00 \\
Nest height & 10 & $1,406.36$ & 13.63 & 0.00 \\
Guild & 10 & $1,406.44$ & 13.71 & 0.00 \\
Global & 25 & $1,377.03$ & 14.3 & 0.00 \\
Percent wooded*guild & 10 & $1,410.35$ & 17.62 & 0.00 \\
Percent wooded & 10 & $1,419.19$ & 26.46 & 0.00 \\
Intercept only & 5 & $1,432.28$ & 29.55 & 0.00 \\
Percent urban & 10 & $1,424.40$ & 31.67 & 0.00 \\
\hline
\end{tabular}

NOTES: Nest-site factor is nest height. Landscape factors are percent urban, percent open, and percent wooded. The global model includes percent urban*guild + percent open + height*guild + wooded*guild.

a subset of the Golden-cheeked Warbler data used here hinted at predator-specific patterns (Stake 2003); Stake concluded that snake predation increased with day of year, was higher in junipers, and decreased with increasing nest height. Our results are consistent with the temporal pattern observed by Stake (2003), but we found that snake predation increased with increasing height. His results also indicated risk of bird predation was higher if the nest was located on a slope or the territory was held by a young male. We did not examine those variables, and consider them surrogates for habitat or landscape features.

Texas ratsnakes (Pantherophis obsoletus) and fire ants usually depredated nests at night. Despite advances in our knowledge of Texas ratsnake ecology, their nocturnal movement patterns and cues used to locate nests remain unknown. Ratsnakes (Pantherophis spp.) in general are believed to use visual cues to locate nests (Mullin and Cooper 1998). Texas ratsnakes depredated both nestlings and eggs at night. Carter et al. (2007) also reported nocturnal predation by eastern ratsnakes (Pantherophis alleghaniensis) on eggs as well as nestlings. Foraging by fire ants is dependent on temperature, and they are not restricted to foraging during certain times of the day (Claborn and
Phillips 1986, Porter and Tschinkel 1987). While fire ants are known to forage in high temperatures (Porter and Tschinkel 1987), activity was highest during the night in summer months in central Texas (Claborn and Phillips 1986). Fire ants may locate nests using chemosensory cues as they systematically move through the habitat.

Day of year and nest age were important predictors of predation risk. Risk of predation by snakes and fire ants increased through the season, and is likely related to increases in temperature causing activity to increase (Vogt et al. 2003, Sperry et al. 2008). Similar to Benson et al. (2010), we found that bird (including cowbird) predation declined with day of year; increased predation coincided with the majority of first warbler nests and the earliest vireo nests. In terms of the age of the nest, old nestlings were at much greater risk of predation than eggs or younger nestlings by all predator groups except fire ants. Older nestlings should provide the most cues to predators, especially visually oriented predators, because they become increasing audible and visible and the adults make frequent trips to the nest to feed young. However, fire ants likely systematically search through the vegetation on foraging forays, allowing them to locate nests before other predators, 

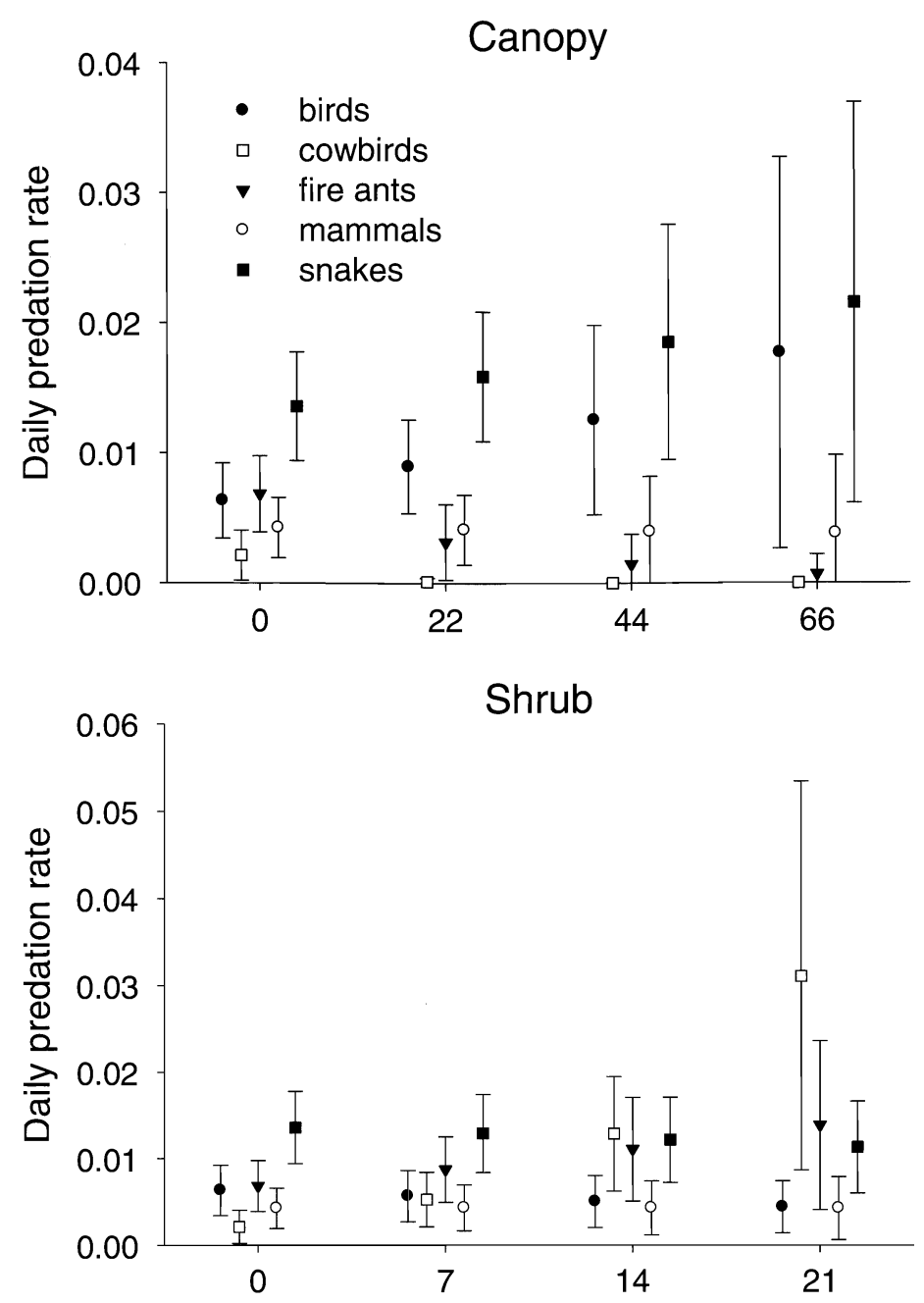

Figure 11.3. Predicted daily predation rate (and $95 \%$ confidence intervals) by predator groups as a function of percent urban in a 5-km radius around the nest at canopy and shrub nests monitored with video cameras in central Texas, 1997-2009.

and may make return visits to nests found with eggs. Stake and Cimprich (2003) noted several visits by ants to nests with eggs.

Landscape composition had a greater influence on predicting nest predator groups than our nestsite variable. This outcome is in accord with the inference that large-scale features constrain and provide context for small-scale factors (Thompson et al. 2002); however, we note that information on nest-site habitat was limited due to few common variables being measured among the studies. Information on the possible drivers for the landscape effect for different predator groups is limited. Currently, it is unknown how snake abundance or habitat use in urban areas differs from rural areas, but Texas ratsnakes are known to prefer wooded areas and associated edges over open habitat (Sperry et al. 2009). If ratsnakes are using the canopy as edge, as postulated by Sperry et al. (2009), their use of the habitat will increase their likelihood of locating nests by chance as they move through the canopy.

The bird species likely driving our landscape results is Western Scrub-Jay (Aphelocoma californica), which was the dominant avian predator in the urban landscape (Reidy et al. 2009). This species prefers juniper-oak scrub and is well adapted to human-altered habitats (Curry et al. 2002). In addition, raptors such as Broad-winged Hawks (Buteo platypterus) and Cooper's Hawks (Accipiter cooperii) are associated with continuous forests with canopy gaps and openings 

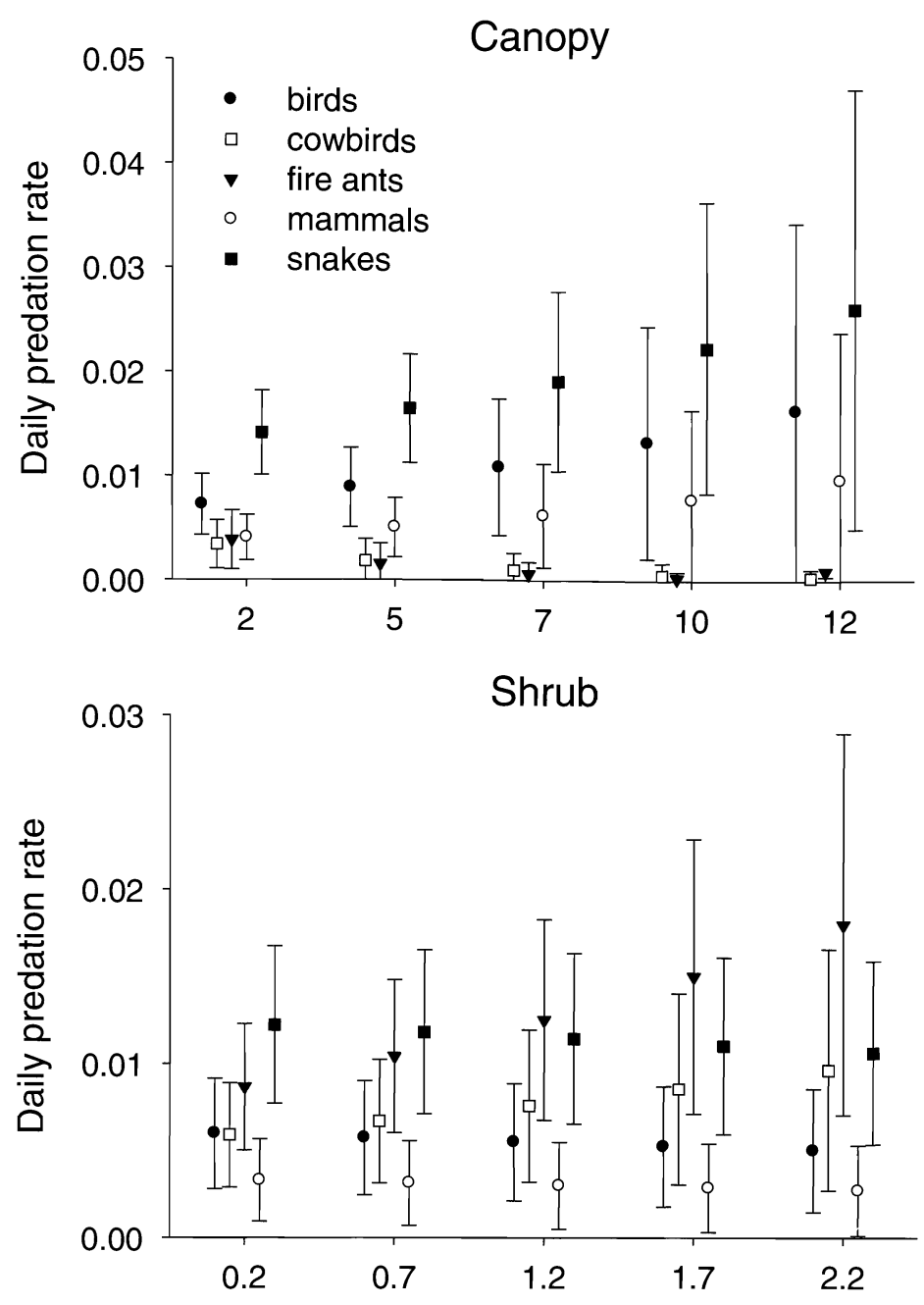

Figure 11.4. Predicted daily predation rate (and $95 \%$ confidence intervals) by predator groups as a function of height at canopy and shrub nests monitored with video cameras in central Texas, 1997-2009.

(Goodrich et al. 1996, Curtis et al. 2006), and Cooper's Hawks are known to tolerate fragmentation and are increasingly urban-adapted (Curtis et al. 2006). As expected, risk of cowbird predation was strongly influenced by the extent of open landcover in the landscape, with much higher predicted predation in more open landscapes. The additive effect should lead to greater bird predation in more fragmented landscapes. We did not measure extent of fragmentation within wooded habitat, and the observed patterns are confounded by lumping species and examining general landscape metrics.

Fire ants are a dominant predator of shrub nesters in this system. Fire ant predation increased in landscapes with greater amounts of anthropogenic disturbance. Vireos had a strong reaction to the presence of fire ants, eliciting attacks and resulting in abandoned nests (Stake and Cimprich 2003). Warbler nests experienced few predations by fire ants, probably due to increased nest height over vireos and preference for junipers, which experienced lower predation. Fire ants are more abundant in oak-dominated habitat than juniper (Claborn 1985), and warblers nesting in juniper-dominated habitat may be safer from fire ant predation. Ant predations on warbler nests were close to edge (Reidy et al. 2008), and predation may increase as warbler habitat experiences more disturbance and fragmentation from highway construction and urban development (Plowes et al. 2007). 
We were unable to determine strong predictors of mammal predation. Due to overall low numbers of mammalian predation events, we had to combine them into one group for analysis. The majority of such predations were in the nestling stage and were diurnal, suggesting that increased activity by adults or young at the nest may alert mammals to the nest location. Other studies in forested habitat within the southeastern United States have also experienced low rates of mammalian predation (Benson et al. 2010, Conner et al. 2010).

Overall, we found support for our hypothesis that the effects of habitat, landscape, nest activity, and temporal factors on the probability of predation vary among predator groups. We suggest that future investigations of nest predation either identify predators, or at least consider who the likely predators are, and consider predator-specific hypotheses. Major nest predators of shrub and canopy nesters at our sites are positively associated with human-altered landscapes. If managers wish to increase nest survival of these endangered birds, both species should benefit by decreasing fragmentation of woodland and shrubland habitat, reducing edge, and decreasing disturbance related to anthropogenic activities, including urban development. Increased knowledge about Texas ratsnakes and Western Scrub-Jays should yield additional insight into the patterns we observed.

\section{ACKNOWLEDGMENTS}

We thank M. Stake and D. Cimprich for data collected on Fort Hood from 1997 to 2002. We thank J. Cornelius, R. Kostecke, and R. Peak for assistance on Fort Hood and D. Koehler and L. O'Donnell for assistance in Austin. We thank two anonymous reviewers for their comments on previous versions of this manuscript. The content of this manuscript does not necessarily reflect the position or policy of the U.S. government or The Nature Conservancy, and no official endorsement should be inferred. Funding was provided by the U.S. Army through cooperative agreements DPW-ENV-97-A-0001 and DPW-ENV-02-A-0001 with The Nature Conservancy of Texas, as well as the U.S. Forest Service.

\section{LITERATURE CITED}

Adams, A. A. Y., S. K. Skagen, and J. A. Savidge. 2007. Population-specific demographic estimates provide insights into declines of Lark Buntings (Calamospiza melanocorys). Auk 124:578-593.
Allen, C. R., D. M. Epperson, and A. S. Garmestani. 2004. Red imported fire ant impacts on wildlife: a decade of research. American Midland Naturalist 152:88-105.

Allison, P. D. 2002. Missing data. Sage University paper series on Quantitative Applications in the Social Sciences 07-137. Sage, Thousand Oaks, CA.

Arcese, P., J. N. M. Smith, and M. I. Hatch. 1996. Nest predation by cowbirds and its consequences for passerine demography. Proceedings of the National Academy of Sciences of the United States of America 93:4608-4611.

Bailey, J. W. 2005. Hierarchical nest-site selection and the effects of habitat characteristics on Black-capped Vireo nest survival. M.S. thesis, University of Missouri, Columbia, MO.

Bailey, J. W., and F. R. Thompson III. 2007. Multiscale nest-site selection by Black-capped Vireos. Journal of Wildlife Management 71:828-836.

Benson, T. J., J. D. Brown, and J. C. Bednarz. 2010. Identifying predators clarifies predictors of nest success in a temperate passerine. Journal of Animal Ecology 79:225-234.

Brawn, J. D., and S. K. Robinson. 1996. Source-sink population dynamics may complicate the interpretation of long-term census data. Ecology 77:3-12.

Burhans, D. E., D. Dearborn, F. R. Thompson III, and J. Faaborg. 2002. Factors affecting predation at songbird nests in old fields. Journal of Wildlife Management 66:240-249.

Burnham, K. P., and D. R. Anderson. 2002. Model selection and multimodel inference: a practical information-theoretic approach. Second edition. Springer, New York, NY.

Campomizzi, A. J., M. L. Morrison, S. L. Farrell, R. N. Wilkins, B. M. Drees, and J. M. Packard. 2009. Red imported fire ants can decrease songbird nest survival. Condor 111:534-537.

Carter, G. M., M. L. Legare, D. R. Breininger, and D. M. Oddy. 2007. Nocturnal nest predation: a potential obstacle to recovery of a Florida Scrub-Jay population. Journal of Field Ornithology 78:390-394.

Chalfoun, A. D., M. J. Ratnaswamy, and F. R. Thompson III. 2002. Songbird nest predators in forestpasture edge and forest interior in a fragmented landscape. Ecological Applications 12:858-867.

Claborn, D. M. 1985. Effect of Solenopsis invicta Buren territoriality on native ants of central Texas. M.S. thesis, Texas Tech University, Lubbock, TX.

Claborn, D. M., and S. A. Phillips. 1986. Temporal foraging activities of Solenopsis invicta (Hymenoptera: Formicidae) and other predominant ants of central Texas. Southwestern Naturalist 31:555-557.

Conner, L. M., J. C. Rutledge, and L. L. Smith. 2010. Effects of mesopredators on nest survival 
of shrub-nesting songbirds. Journal of Wildlife Management 74:73-80.

Crother, B. I. (editor). 2008. Scientific and standard English names of amphibians and reptiles of North American north of Mexico. Herpetological Circular No. 37. Society for the Study of Amphibians and Reptiles, Salt Lake City, UT. < http://www.ssarherps. org/pdf/HC_37_6thEd.pdf > (22 September 2010).

Curry, R. L., A. T. Peterson, and T. A. Langen. 2002. Western Scrub-Jay (Aphelocoma californica). Birds of North America No. 712, Academy of Natural Sciences, Philadelphia, PA.

Curtis, O. E., R. N. Rosenfield, and J. Bielefeldt. 2006. Cooper's Hawk (Accipiter cooperii). Birds of North America No. 75, Academy of Natural Sciences, Philadelphia, PA.

Filliater, T. S., R. Breitwisch, and P. M. Nealen. 1994. Predation on Northern Cardinal nests: does choice of nest site matter? Condor 96:761-768.

German, D., D. D. Diamond, L. F. Elliott, A. TreuerKuehn, K. Ludeke, and J. Scott. 2009. Texas Ecological Systems Project phase 1 interpretive booklet. Accompanies Ecological Systems GIS Data Layer (internal document). Texas Parks and Wildlife Department, Austin, TX. <http://www.tpwd.state .tx.us/landwater/lands/maps/gis/tescp/index > (19 August 2010).

Goodrich, L. J., S. C. Crocoll, and S. E. Senner. 1996. Broad-winged Hawk (Buteo platypterus). Birds of North America No. 218, Academy of Natural Sciences, Philadelphia, PA.

Granfors, D. A., P. J. Pietz, and L. A. Joyal. 2001. Frequency of egg and nestling destruction by female Brown-headed Cowbirds at grassland nests. Auk 118:765-769.

Grant, T. A., T. L. Shaffer, E. M. Madden., and P. J. Pietz. 2005. Time-specific variation in passerine nest survival: new insights into old questions. Auk 122:661-672.

Grzybowski, J. A. 1995. Black-capped Vireo (Vireo atricapillus). Birds of North America No. 181, Academy of Natural Sciences, Philadelphia, PA.

Ladd, C., and L. Gass. 1999. Golden-cheeked Warbler (Dendroica chrysoparia). Birds of North America No. 420, Academy of Natural Sciences, Philadelphia, PA.

Lahti, D. C. 2009. Why we have been unable to generalize about bird nest predation. Animal Conservation 12:279-281.

Martin, T. E. 1993. Nest predation and nest sites: new perspectives on old patterns. BioScience 43:523-532.

Martin, T. E., J. Scott, and C. Menge. 2000. Nest predation increases with parental activity: separating nest site and parental activity effects. Proceedings of the Royal Society of London, Series B 267:2287-2293.
Mullin, S. J., and R. J. Cooper. 1998. The foraging ecology of the gray rat snake (Elaphe obsolete spiloides): visual stimuli facilitate location of arboreal prey. American Midland Naturalist 140:397-401.

Newton, I. 1998. Population limitation in birds. Academic Press, London, UK.

Newton, I. 2004. Population limitation in migrants. Ibis 146:197-226.

Plowes, R. M., J. G. Dunn, and L. E. Gilbert. 2007. The urban fire ant paradox: native fire ants persist in an urban refuge while invasive fire ants dominate natural habitats. Biological Invasions 9:825-836.

Porter, S. D., and W. R. Tschinkel. 1987. Foraging in Solenopsis invicta (Hymenoptera: Formicidae): effects of weather and season. Environmental Entomology 16:802-808.

Pulich, W. M. 1976. The Golden-cheeked Warbler: a bioecological study. Texas Parks and Wildlife Department, Austin, TX.

Reidy, J. L., M. M. Stake, and F. R. Thompson III. 2008. Golden-cheeked Warbler nest mortality and predators in urban and rural landscapes. Condor 110:458-466.

Reidy, J. L., F. R. Thompson III, and R. G. Peak. 2009. Factors affecting Golden-cheeked Warbler nest survival in urban and rural landscapes. Journal of Wildlife Management 73:407-413.

Richardson, T. W., T. Gardali, and S. H. Jenkins. 2009. Review and meta-analysis of camera effects on avian nest success. Journal of Wildlife Management 73:287-293.

Robinson, S. K., S. I. Rothstein, M. C. Brittingham, L. J. Petit, and J. A. Grzybowski. 1995. Ecology and behavior of cowbirds and their impact on host populations. Pp. 428-460 in T. E. Martin and D. M. Finch (editors), Ecology and management of neotropical migratory birds: a synthesis and review of critical issues. Oxford University Press, New York, NY.

Shaffer, T. L., and F. R. Thompson III. 2007. Making meaningful estimates of nest survival with modelbased methods. Studies in Avian Biology 34:84-95.

Sperry, J. H., D. A. Cimprich, R. G. Peak, and P. J. Weatherhead. 2009. Is nest predation on two endangered bird species higher in habitats preferred by snakes? Ecoscience 16:111-118.

Sperry, J. H., R. G. Peak, D. A. Cimprich, and P. J. Weatherhead. 2008. Snake activity affects seasonal variation in nest predation risk for birds. Journal of Avian Biology 39:379-383.

Stake, M. M. 2003. Golden-cheeked Warbler nest predators and factors affecting nest predation. M.S. thesis, University of Missouri, Columbia, MO.

Stake, M. M., and D. A. Cimprich. 2003. Using video to monitor predation at Black-capped Vireo nests. Condor 105:348-357. 
Stake, M. M., J. Faaborg, and F. R. Thompson III. 2004. Video identification of predators at Goldencheeked Warbler nests. Journal of Field Ornithology 75:337-344.

Stake, M. M., F. R. Thompson III, J. Faaborg, and D. E. Burhans. 2005. Patterns of snake predation at songbird nests in Missouri and Texas. Journal of Herpetology 39:215-222.

Thompson, F. R., III. 2007. Factors affecting nest predation on forest songbirds in North America. Ibis 149:98-109.

Thompson, F. R., III, and D. E. Burhans. 2003. Predation of songbird nests differs by predator and between field and forest habitats. Journal of Wildlife Management 67:408-416.

Thompson, F. R., III, T. M. Donovan, R. M. DeGraaf, J. Faaborg, and S. K. Robinson. 2002. A multi-scale perspective of the effects of forest fragmentation on birds in eastern forests. Studies in Avian Biology 25:8-19.

U.S. Fish and Wildlife Service. 1991. Black-capped Vireo (Vireo atricapillus) recovery plan. USFWS Endangered Species Office, Albuquerque, NM.

Vogt, J. T., W. A. Smith, R. A. Grantham, and R. E. Wright. 2003. Effects of temperature and season on foraging activity of red imported fire ants (Hymenoptera: Formicidae) in Oklahoma. Physiological Ecology 32:447-451.

Williams, G. E., and P. B. Wood. 2002. Are traditional methods of determining nest predators and nest fates reliable? An experiment with Wood Thrushes (Hylocichla mustelina) using miniature video cameras. Auk 119:1126-1132.

Wilson, R. R., and R. J. Cooper. 1998. Acadian Flycatcher nest placement: does placement influence reproductive success? Condor 100:673-679. 